\title{
Origin of Magnetic Instability in Sediment Cores From the Central North Pacific
}

\author{
D. V. KENT ${ }^{1}$ AND W. LOWRIE \\ Lamont-Doherty Geological Observatory of Columbia University \\ Palisades, New York 10964
}

\begin{abstract}
Previous paleomagnetic studies on deep-sea sediment cores from the central North Pacific have shown that the natural remanent magnetization (NRM) of these 'red clay' sediments was unstable below several meters depth in each core. It was also noted that the magnetic instability was related to the presence of a relatively large low-coercivity component of magnetization. The purpose of this investigation was to characterize the rock magnetic properties in three select cores from this region to determine the physical origin of the unstable magnetization. The principal findings of our investigation were as follows. (1) The ability to acquire a viscous remanent magnetization increased with depth in each core, particularly at about the level where unstable magnetization became evident. (2) The magnitude and stability of the observed NRM of the magnetically unstable section of each core can be explained by a viscous remanence acquired in the presence of the earth's magnetic field over a period of time ranging from only several weeks to several thousands of years. (3) The unstable magnetization, believed to be of viscous origin, was attributed to the presence of a magnetic mineral similar in structure and composition to maghemite. This mineral may have resulted from the low-temperature oxidation of very fine grained magnetite at about the time of deposition of these sediments. The extrapolated ages of the levels at which unstable magnetization becomes evident in the cores from this region suggest a close correspondence with the times of established upper Cenozoic climatic changes. Considerations of the alteration of the sedimentary regime resulting from the changes in climate can provide a satisfactory explanation for the observed change in magnetic properties.
\end{abstract}

In a paleomagnetic study of a large suite of sediment cores from the North Pacific Opdyke and Foster [1970] reported a marked instability of magnetization that occurred with depth in most cores of 'red clay' lithology. The sediment cores in which the instability of magnetization was noted were located within a region of the central North Pacific characterized by a generally low sediment thickness and by Brunhes epoch sedimentation rates of the order of only several millimeters per thousand years (Figure 1). Both the low sedimentation rate and the small sediment thickness probably are related to the low biogenic productivity in the area [Fleming, 1957] and to the large distances from continental sediment sources. The marginal trenches surrounding much of the North Pacific basin also act as sediment traps and inhibit bottom transport of sediment to the center of the basin.

The magnetic instability in these cores was characterized by a decrease in the quality of the natural remanent magnetization (NRM) directional data with depth. Alternating field partial demagnetization techniques were able to enhance only marginally the coherence of the data in the unstable sections of the core. The directional instability was apparently associated with an increase in a soft component of magnetization with depth.

A color change occurs in these cores at several meters depth, below which the remanent directions are uninterpretable. The color change has been ascribed to an increase in abundance of manganese micronodules with depth [Bramlette, 1961]. It has been suggested that the decrease in magnetic stability was in some way related to this increase in abundance of micronodules [Opdyke and Foster, 1970].

The purpose of this study was to investigate in more detail the nature of the magnetic instability and its physical origin in three selected cores from the area. Additional magnetic data were obtained by utilizing samples originally measured and

${ }^{1}$ Also at Department of Geology, Columbia University, Palisades, New York 10964.

Copyright $@ 1974$ by the American Geophysical Union. reported by Opdyke and Foster [1970]. New samples were cut from the cores where it was necessary and possible. All magnetic remanence measurements reported here were made on dry sediment.

\section{Core Descriptions}

The locations of the three cores selected for study (V20-98. V20-102, and RC10-158) are shown in Figure 1. All were raised from water depths exceeding $5200 \mathrm{~m}$. The lithologies of the cores were similar and consisted of clay of moderate brown color, darkening with depth, and structureless in appearance save for some indication of bioturbation, especially in the top few tens of centimeters of each core. The mean grain size of the sediment was generally of the order of $1 \mu \mathrm{m}$ (Table 1), and the coarse-sized fraction $(>63 \mu \mathrm{m})$, where it was present, consisted chiefly of manganese micronodules. The sediment was carbonate free and generally barren of any visible fossils. A highly altered ash(?) was present below an 880-cm depth in V20-98.

The nature of the magnetic instability problem in cores from this area is illustrated by the data from V20-102 (Figure 2). The coherence of the NRM inclination direction decreases with depth, especially below about $445 \mathrm{~cm}$ in the core. Partial af demagnetization resulted in an improved magnetic record for the upper section of the core. The mean inclination of this upper section, irrespective of sign, is not significantly different from the axial dipole field inclination at the site $\left(50.5^{\circ}\right)$, with only a small scatter about the mean $\left(47.9^{\circ} \pm 9^{\circ}\right)$. Polarity transitions are represented simultaneously in both inclination and declination, although declination shows some additional shifts due to the lack of internal orientation of these cores upon extrusion. The pattern of polarity changes with depth can be correlated with the established magnetic reversal sequence for about the past 2 m.y. [Dalrymple, 1972].

On the other hand, the remanent inclinations in the section of the core deeper than about a $445-\mathrm{cm}$ depth remained scattered after partial demagnetization, and changes in the sign of the inclinations were generally not accompanied by 


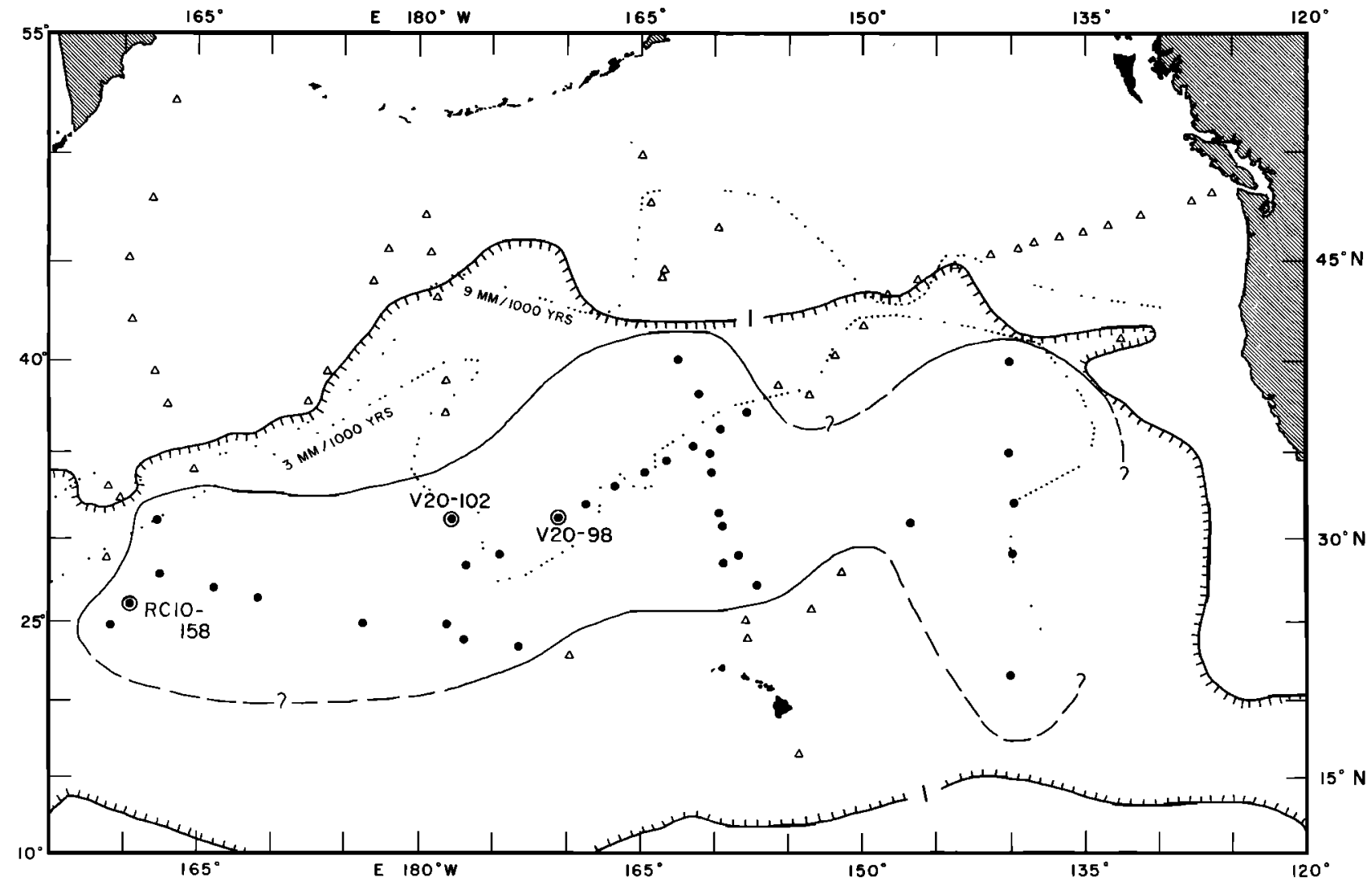

Fig. 1. Locations of cores studied paleomagnetically by Opdyke and Foster [1970] in the North Pacific. Solid circles indicate cores that are magnetically unstable at depth; open triangles indicate more stable cores. Solid line (breaks indicate uncertainty) delineates region within which unstable cores occur. Also shown are Brunhes epoch sedimentation rate contours of 3 and $9 \mathrm{~mm} / 1000 \mathrm{yr}$ [Opdyke and Foster, 1970] (dotted lines) and the 100-m (approximately) transparent sediment layer isopach [Ewing et al., 1968] (hachured line). Area within the hachures has a transparent sediment thickness generally less than $100 \mathrm{~m}$.

appreciable shifts in declination. A recognizable pattern of polarity changes did not emerge in this section of the core. The level in the core, when it is viewed from bottom to top, at which the partially demagnetized inclination directions become less scattered and have an average value close to the expected dipole inclination is defined as the termination of magnetic instability. The sedimentation rates in the upper sections of the three cores examined, as well as the depth and extrapolated age of the termination of magnetic instability, are included in Table 1.
To obtain a more representative estimate of the age at which the termination occurs in this region, the age of this level was determined by extrapolation from the stable magnetic stratigraphy to the onset of unstable behavior in North Pacific cores previously studied by Opdyke and Foster [1970]. Twenty-four cores possessing a reasonably well defined Brunhes-Matuyama reversal boundary were used. Although the method of estimating the time of instability termination may have contributed to the spread in ages, these ages form a bimodal distribution with a peak at about 1.5

TABLE 1. Core Locations and Lengths and the Mean Grain Size of the Sediment at Two Levels in Each Core

\begin{tabular}{|c|c|c|c|c|c|c|c|c|c|}
\hline \multirow[b]{2}{*}{ Core } & \multirow[b]{2}{*}{ Location } & \multirow[b]{2}{*}{$\begin{array}{c}\text { Water } \\
\text { Depth, } \\
\text { corrected } \\
\text { m }\end{array}$} & \multirow[b]{2}{*}{$\begin{array}{l}\text { Core } \\
\text { Length, } \\
\text { cm }\end{array}$} & \multicolumn{2}{|c|}{$\begin{array}{l}\text { Sedimentation Rates, * } \\
\mathrm{mm} / 1000 \mathrm{yr}\end{array}$} & \multicolumn{2}{|c|}{$\begin{array}{l}\text { Termination of } \\
\text { Magnetic Instabilityt }\end{array}$} & \multicolumn{2}{|c|}{$\begin{array}{l}\text { Total Sediment } \\
\text { Grain Sizes }\end{array}$} \\
\hline & & & & $\begin{array}{l}\text { Brunhes } \\
\text { Epoch }\end{array}$ & $\begin{array}{l}\text { Olduvai } \\
\text { Event-Base } \\
\text { of Brunhes }\end{array}$ & $\begin{array}{l}\text { Depth in } \\
\text { Core, } \\
\text { cm }\end{array}$ & $\begin{array}{c}\text { Extrapolated } \\
\text { Age, } \\
\text { m.y. B.P. }\end{array}$ & $\begin{array}{l}\text { Depth in } \\
\text { Core } \\
\text { cm }\end{array}$ & $\begin{array}{l}\text { Mean Grain } \\
\text { Size, } \mu m\end{array}$ \\
\hline V20-98 & $\begin{array}{l}31^{\circ} 10^{\prime} \mathrm{N}, \\
171^{\circ} 35^{\prime} \mathrm{W}\end{array}$ & 5673 & 975 & 3.2 & 1.6 & 475 & 2.28 & $\begin{array}{l}\text { Top } \\
292\end{array}$ & $\begin{array}{l}0.99 \\
0.87\end{array}$ \\
\hline V20-102 & $\begin{array}{l}31^{\circ} 11^{\prime} \mathrm{N}, \\
177^{\circ} 49^{\prime} \mathrm{W}\end{array}$ & 5216 & 972 & 2.5 & 1.4 & 445 & 2.62 & $\begin{array}{l}\text { Top } \\
942\end{array}$ & $\begin{array}{l}4.57 \\
0.86\end{array}$ \\
\hline RCI0-158 & $\begin{array}{l}28^{\circ} 06^{\prime} \mathrm{N}, \\
160^{\circ} 36^{\prime} \mathrm{E}\end{array}$ & 5892 & 986 & 1.5 & 1.2 & 305 & 2.38 & $\begin{array}{l}\text { Top } \\
945\end{array}$ & $\begin{array}{l}1.09 \\
0.55\end{array}$ \\
\hline
\end{tabular}

*Calculated from core magnetics data by Opdyke and Foster [1970]. An age of 0.69 m.y. was used for the BrunhesMatuyama boundary, and an age of $1.86 \mathrm{~m} . \mathrm{y}$. was used for the base of the olduvai event.

tSee text for definition. Extrapolated age of termination of instability was obtained by assuming the sedimentation rate calculated between the base of the Brunhes and the base of the olduvai in each core.

5From Horn et al. [1968]. 

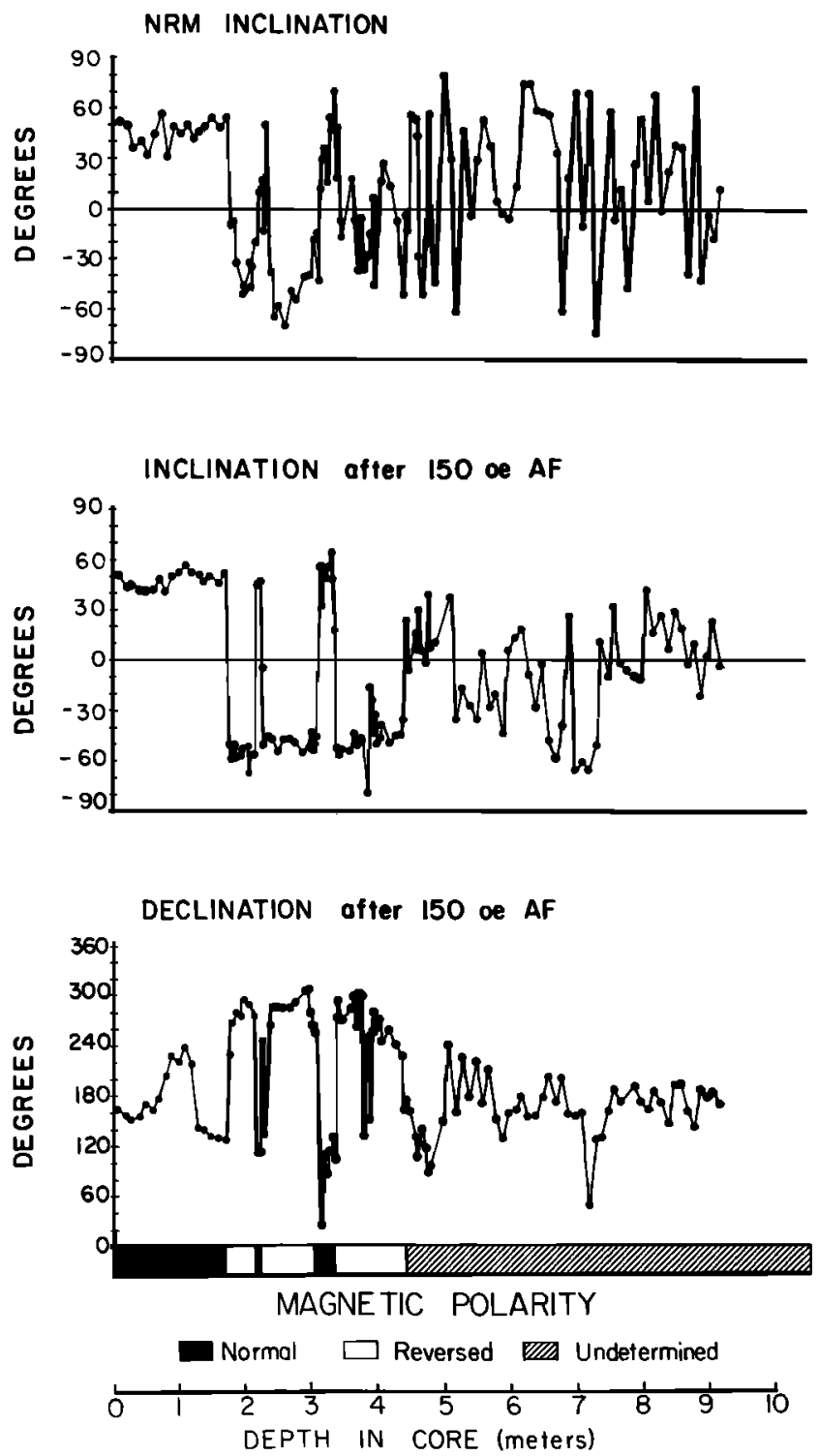

Fig. 2. The variation of uncleaned NRM inclination and the inclination and declination after partial demagnetization in a $150-\mathrm{Oe}$ alternating field, with depth in core V20-102.

m.y. B.P. and a more prominent grouping at about 3.0 m.y. B.P. (Figure 3). These ages, particularly the one at 3.0 m.y. B.P., coincide with established sedimentological changes in the North Pacific associated with climatic change, as will be discussed below. The three cores examined here are associated with the population having the older mean age.

\section{Natural Remanent Magnetic Properties}

The relationship between the coherence of the remanent directions and the relative magnitude of a low-coercivity component of magnetization is readily seen in Figure 4. The variation of magnetically cleaned remanent inclinations with depth is shown for two cores. A measure of the relative importance of the soft component of magnetization was devised as follows. For each core the ratio $f(H)$ of the remanent intensity removed by partial af demagnetization in a peak field $H$ (in oersteds) to the original NRM intensity was plotted as a function of depth in the core. In both cores this ratio $f(50)$ or $f(150)$ ) was markedly larger in the lower magnetically unstable sections of the cores and exhibited relatively sharp decreases at the levels defining the terminations of magnetic instability. A soft component of magnetization, with a coercivity less than 50 or 150 Oe, makes up $80-90 \%$ of the NRM below the termination level but only about $20-40 \%$ above. Several large values of this ratio do occur in the upper apparently stable sections of the core. However, most of them occur at or near polarity changes and may be due to relatively low original magnetization intensity often associated with polarity transitions [Opdyke et al., 1973].

Progressive af demagnetization of the NRM's of several specimens from each core showed depth-dependent characteristics illustrated in Figure 5 by two specimens, one near the top and the other near the base of core RC10-158. After removal of a soft component of magnetization in about a 50-Oe alternating field, the NRM of the specimen at a $16-\mathrm{cm}$ depth in core showed stable behavior against alternating fields. The remanent intensity gradually decreased, and the remanent directions coalesced with increasing alternating fields. In contrast, the NRM of the specimen at a $706-\mathrm{cm}$ depth in the core displayed unstable behavior. The remanent intensity decreased rapidly, whereas the remanent directions continued to change significantly with greater alternating fields. After demagnetizing in fields greater than $100 \mathrm{Oe}$, the remanence of this specimen changed substantially even during measurements.

The NRM's of several specimens from each core were also thermally demagnetized at progressively higher temperatures. Depth-dependent characteristics were again noted, as is shown for three specimens from core V20-102 (Figure 6). The NRM of specimens from above the depth level of the termination of instability (Table 1) achieved stable directions after $250^{\circ} \mathrm{C}$. The stable NRM directions were apparently carried by a magnetic phase with blocking temperatures of about $550^{\circ} \mathrm{C}$, whereas the secondary component was carried by a phase with blocking temperatures of about $200^{\circ} \mathrm{C}$. In contrast, the NRM of the specimen from the magnetically unstable section of the core was dominated by a low blocking temperature. If a stable component of NRM exists in this specimen, it may be apparent only after thermal demagnetization at temperatures above $500^{\circ} \mathrm{C}$.

The thermal demagnetization of an isothermal remanent magnetization (IRM) produced in a $3000-O e$ field in an adjacent specimen (702 $\mathrm{cm}$ (IRM)) did not reveal an appreciable low blocking temperature component. The strong-field IRM should represent the total magnetic component in the sediment. Apparently, only the more thermally unstable portion of the total magnetic blocking temperature spectrum con-

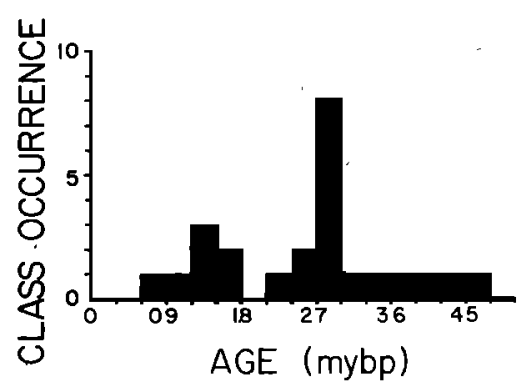

Fig. 3. Histogram of the age of the termination of magnetic instability in 24 cores from the central North Pacific. The age of the termination level was determined by extrapolating down from the oldest recognized magnetic event or epoch reversal in each core. Only cores with a reasonably well defined Brunhes-Matuyama reversal boundary were used. 
V2O-98

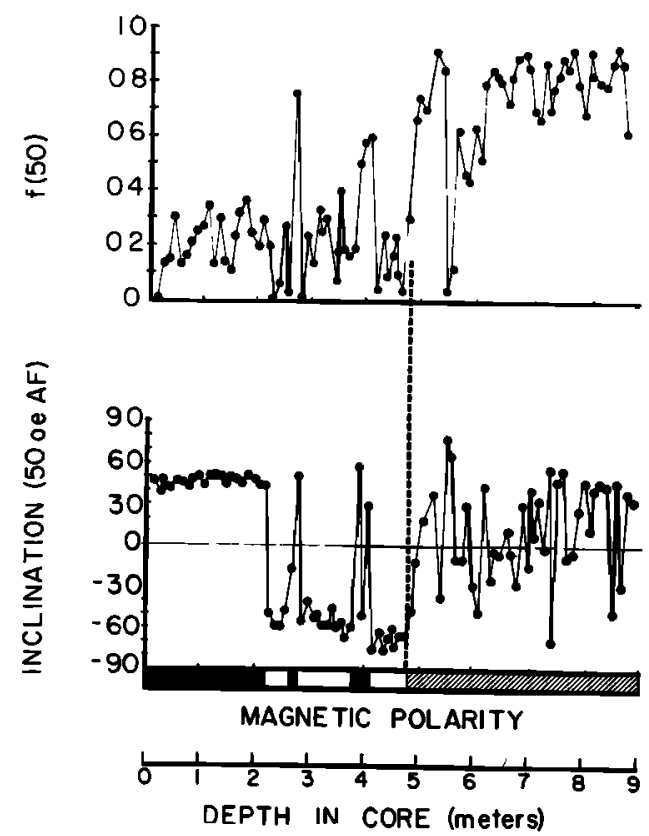

V20-102

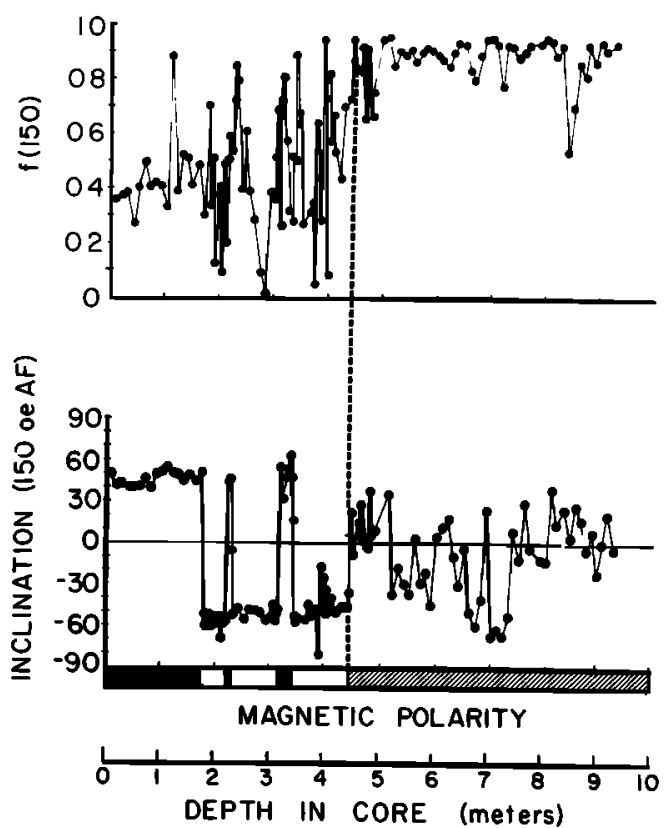

Fig. 4. Variation of the soft component of magnetization $(f(50)$ and $f(150))$ and inclination with depth in two cores from the central North Pacific. Solid band indicates normal polarity; open band, reversed polarity; hachured band, undetermined.

tributes to the NRM in the unstable section of the core. This thermally unstable portion must make only a small contribution to the strong-field IRM.

\section{Viscous Remanent Magnetization}

It is well known that viscous remanent magnetization (VRM) results in a low-coercivity component of NRM that increases with time [Thellier, 1938]. A series of experiments was performed on five specimens from each core to determine to what extent VRM is important in these cores. After partial demagnetization in $300 \mathrm{Oe}$ (af), each specimen was allowed to remain in a field-free space overnight. The specimens were then placed in a known orientation to a uniform 1.0-Oe field after initial measurements of their remanent magnetization. The remanences were remeasured at approximately logarithmically spaced intervals over a period of 1000 hours. All remanence measurements were made on a slow-spin magnetometer [Foster, 1966]. The time spent measuring the remanence of each specimen (outside the control field) was less than $1 \mathrm{~min}$.

For each specimen the acquired IRM $\Delta J$ increased approximately linearly with the logarithm of time ( $t$ in hours), according to the form

$$
\Delta J=S \log t+\text { const }
$$

which is characteristic of VRM [Thellier, 1938; Nagata, 1961]. Typical results are shown in Figure 7 for specimens from RC10-158. A magnetic viscosity coefficient $S$ was determined for each specimen from the slope of the best-fitting line through the data points. The values of $S$, together with the VRM acquired by the specimens in a 1.0-Oe field in 1000 hours, their NRM intensities, and their magnetization polarities ( $N$ for normal, $R$ for reversed), are shown in Table 2. The VRM that could be acquired in 1000 hours in a field of 0.4 Oe (approximately equivalent to the ambient field at the core sites) was calculated for each specimen on the assumption that the viscosity coefficient is linearly proportional to field in this range [Shimizu, 1960].

In each of the cores examined the magnetic viscosity coefficient $S$ decreased from the bottom to the top of the cores by a factor of between 3 and 6 . However, the variation of $S$ with depth was not uniform but showed the most rapid rate of decrease between 3 and $5 \mathrm{~m}$ in each core (Figure 8). The termination of magnetic instability in each case occurs within this zone of rapid decrease of $S$.

Below the defined terminations of instability in these cores the VRM acquired in a 1.0-Oe field in only 1000 hours ex-

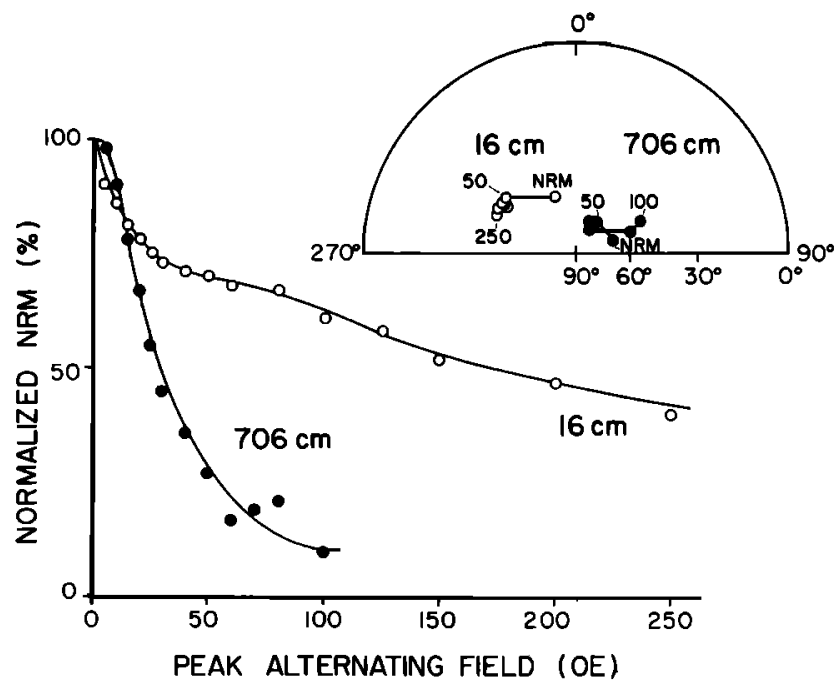

Fig. 5. Change in relative intensity and direction with progressive af demagnetization of the NRM of specimens from two levels (16 and $706 \mathrm{~cm}$ ) in core RC10-158. Both NRM's have positive inclinations. Declination direction is arbitrary for each. 


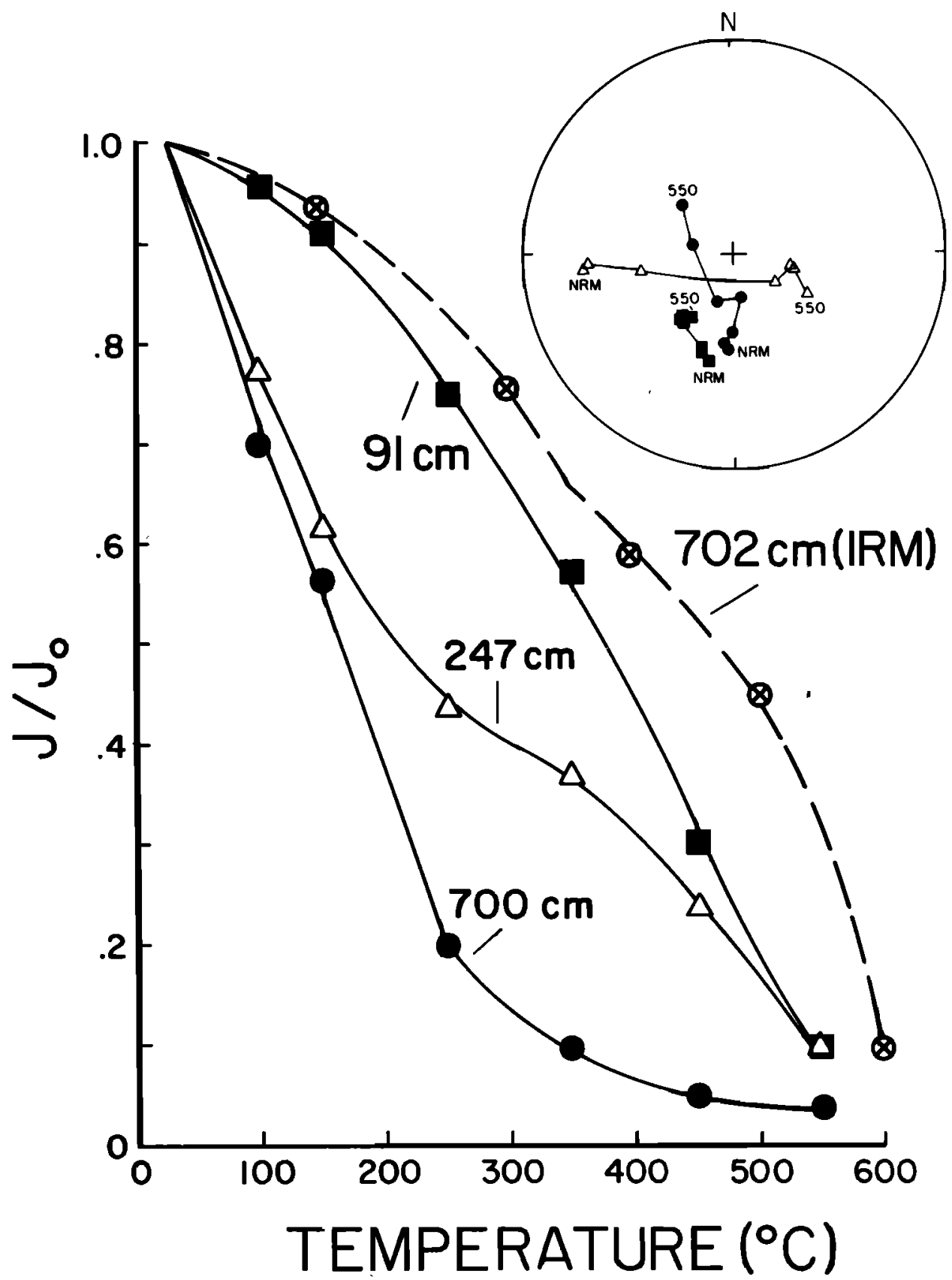

Fig. 6. Change in relative intensity and direction with progressive thermal demagnetization of the NRM of specimens from three levels $(91,247$, and $700 \mathrm{~cm})$ in core V20-102. The NRM of the specimen from $247 \mathrm{~cm}$ has a negative inclination. Declination direction is arbitrary for each specimen. The change in intensity with progressive thermal-demagnetization of a high-field IRM given to a specimen from a 702-cm depth in core is also shown $\left(702 \mathrm{~cm}\right.$ (IRM)). Ambient fields up to $100 \gamma$ may have been present; temperatures are accurate to $\pm 15^{\circ} \mathrm{C}$.

ceeded the NRM intensities of all but one of the specimens. It is not known for what length of time a VRM could be acquired by these specimens at the rate observed over 1000 hours. However, calculations show that a period of time ranging from only several weeks to 10 years would be sufficient for all but one of these specimens to acquire VRM's in a 0.4-Oe field that is equal in magnitude to their observed NRM's; the specimen at a $543-\mathrm{cm}$ depth in core V20-102 would require 10,000 years. However, it may be invalid to extrapolate the measured values of $S$ over geologic times. For example, on the basis of the observed values of $S$ for the stable specimens, the NRM should consist of a very appreciable VRM component in a relatively short period of time. This large soft component would be reflected in a much lower stability against alternating fields than was observed. Thus the VRM component of these samples must approach saturation in a relatively short period of time.

Relatively short period exposures to fields of different intensities and directions, which were undoubtedly experienced by the cores and specimens during handling and storage, would result in complex resultant VRM's. These may account for the incoherence of the magnetic record below the termination of instability in these cores, since the NRM of this sediment must be almost entirely of viscous origin. The relatively uniform declination direction observed in the lower sections of the cores (i.e., V20-102 in Figure 2) is believed to be a result 


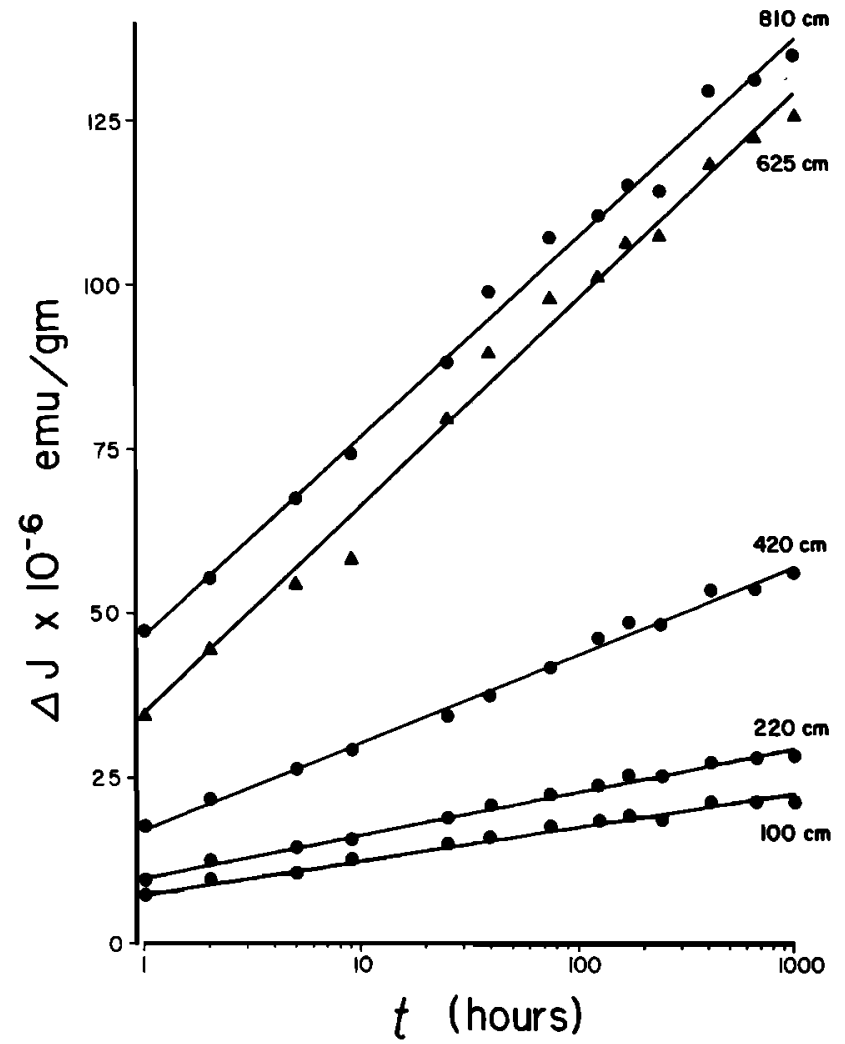

Fig. 7. Increase in remanent magnetization with time in a 1.0-Oe direct field in five specimens from core RC10-158. The best-fitting line to the data points is shown for each specimen. The slope of the line is defined as the magnetic viscosity coefficient $S$. A value of $1 \times 10^{-5}$ $\mathrm{emu} / \mathrm{g}$ has been subtracted from each data point of the specimen from $625 \mathrm{~cm}$ to avoid confusion with the specimen from $810 \mathrm{~cm}$.

of VRM acquired during storage of the cores at LamontDoherty Geological Observatory with their longitudinal axes essentially perpendicular to the ambient field $(0.59 \mathrm{Oe})$.

Each VRM acquired over 1000 hours was progressively demagnetized in alternating fields to determine the field necessary to randomize $50 \%$ (median destructive field (MDF)) and $90 \%$ (destructive field (DF)) of the original remanence. These fields and the MDF for the NRM's of the same specimens are shown in Table 2. It has been established that for VRM's produced in low fields the magnetic hardness is proportional to the logarithm of the acquisition time and is not strongly dependent on the acquisition field [Rimbert, 1959]. It is therefore possible to obtain another estimate of the length of time over which the NRM's were acquired, if it is assumed that they are entirely of viscous origin, by using the relationship

$$
\log t=\left(H_{t} / H_{1000 \mathrm{hr}}\right) \times \log (1000 \mathrm{hr})
$$

where $t$ is the time over which the NRM may have been acquired by viscous buildup and $H_{t}$ and $H_{1000 \mathrm{hr}}$ are the demagnetizing fields for the NRM and the 1000-hour VRM, respectively. Inserting typical values for the MDF of the NRM and VRM (Table 2) for an unstable specimen (V20$102,701 \mathrm{~cm})$ and then for a stable specimen (V20-102, $86 \mathrm{~cm})$ yields for the unstable case

$$
\log t \cong 6 \quad t \cong 10^{\circ} \text { hours } \cong 100 \text { years }
$$

and for the stable case

$$
\log t \cong 18 \quad t \cong 10^{18} \text { hours } \cong 10^{12} \text { years }
$$

The result for the unstable specimen supports the view that most of the observed NRM is of VRM origin acquired over a relatively short period of time. The $10^{12}$-year age estimate for the stable specimen reflects the observation that only a small proportion of the NRM of this specimen is VRM.

\section{Coercivity SPEctra}

After the af demagnetization characteristics of the NRM and the 1000-hour VRM were determined, the anhysteretic remanent magnetization (ARM) produced in a 2000-Oe peak alternating field with a 0.5 -Oe direct bias field and the saturation isothermal remanent magnetization (SIRM) produced

\begin{tabular}{|c|c|c|c|c|c|c|c|c|}
\hline \multirow[b]{3}{*}{ Core } & \multirow{3}{*}{$\begin{array}{l}\text { Depth in } \\
\text { Core, cm }\end{array}$} & \multirow{2}{*}{\multicolumn{4}{|c|}{$\begin{array}{c}\text { Magnetization, } \\
\times 10^{-6} \text { emu } / \mathrm{g}\end{array}$}} & \multicolumn{3}{|c|}{$\begin{array}{c}\text { Demagnetizing Field, } \\
\text { peak Oe }\end{array}$} \\
\hline & & & & & & \multirow{2}{*}{$\begin{array}{c}H_{d} \\
\left(\mathrm{VRM}_{1}, 0,1000\right)\end{array}$} & \multirow{2}{*}{$\begin{array}{c}H_{m d} \\
\left(\mathrm{VRM}_{1.0,1000}\right)\end{array}$} & \multirow{2}{*}{$\begin{array}{l}H_{m d} \\
\text { (NRM) }\end{array}$} \\
\hline & & $S_{1.0}$ & $\mathrm{VRM}_{1} .0,1000$ & $\mathrm{VRM}_{0}: 4,1000$ & NRM & & & \\
\hline \multirow[t]{5}{*}{ V20-98 } & 162 & 7.6 & 27.1 & 10.8 & $61.6(N)$ & 75 & 20 & 120 \\
\hline & 442 & 11.6 & 39.4 & 15.4 & $14.1(R)$ & 53 & 18 & 150 \\
\hline & 575 & 19.4 & 63.6 & 25.4 & 31.9 & 51 & 18 & 40 \\
\hline & 612 & 19.0 & 65.7 & 26.3 & 41.5 & 51 & 18 & 30 \\
\hline & 852 & 23.2 & 108.1 & 43.2 & 59.7 & 58 & 18 & 30 \\
\hline \multirow[t]{5}{*}{ V20-102 } & 86 & 5.7 & 24.5 & 9.8 & $47.6(N)$ & 63 & 20 & 120 \\
\hline & 253 & 6.7 & 28.2 & 11.3 & $28.8(R)$ & 47 & 18 & 120 \\
\hline & 543 & 14.2 & 59.5 & 23.8 & 61.1 & 40 & 15 & 30 \\
\hline & 701 & 14.8 & 66.3 & 26.5 & 22.9 & 41 & 15 & 30 \\
\hline & 851 & 19.2 & 86.8 & 34.7 & 39.3 & 40 & 15 & 50 \\
\hline \multirow[t]{5}{*}{ RCl0-158 } & 100 & 5.0 & 22.6 & 9.0 & $16.0(N)$ & 85 & 20 & 250 \\
\hline & 220 & 6.5 & 29.5 & 11.8 & $13.6(R)$ & 66 & 18 & 250 \\
\hline & 420 & 13.3 & 56.9 & 22.8 & 22.0 & 65 & 18 & 33 \\
\hline & 625 & 31.3 & 139.0 & 55.6 & 36.3 & 45 & 18 & 33 \\
\hline & 810 & 30.3 & 137.3 & 54.9 & 44.9 & 39 & 15 & 33 \\
\hline
\end{tabular}

TABLE 2. Results of VRM Experiments in Comparison With Magnitudes and Stabilities of NRM's of Five Specimens From Each of Three Cores Studied

The magnetic viscosity coefficient $S_{1,0}$ is for the VRM produced in a 1.0-0e field over 1000 hours (VRM $1.0,1000$ ). The VRM that would have been produced in a $0.4-0$ field over 1000 hours $\left(V_{R M} 0.4,1000\right.$ ) was calculated by assuming a linear relationship between $S$ and applied field. The alternating field necessary to destroy $90 \%$ of the acquired VRM ( $H_{d}$ $\left(V_{R M}, 0,1000\right)$ ) and $50 \%$ of the VRM and $50 \%$ of the original NRM ( $H_{m d}\left(V_{R M}, 0,1000\right)$ and $H_{m d}$ (NRM), respectively) are also shown. Pelarity of NRM ( $N$ is normal, $R$ is reversed) is indicated for stable specimens. 


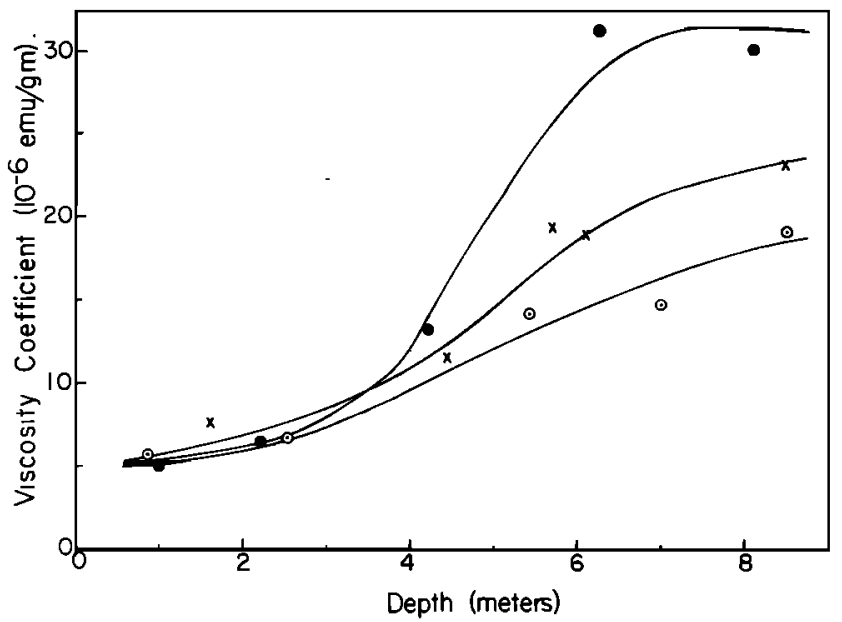

Fig. 8. Variation with depth of the magnetic viscosity coefficient in three cores from the central North Pacific. A time base was not used because of the lack of time stratigraphic control in the lower sections in the cores. Solid circles represent core RC10-158; crosses, core V20-98; dotted circles, core V20-102.

with a 2000-Oe direct field were progressively demagnetized in alternating fields. Typical af demagnetization characteristics of these remanences observed in the core specimens are shown in Figure 9. The total spectrum of coercivities in the specimens can be estimated from the af demagnetization of A RM [Larson et al., 1969] or SIRM. In all specimens studied all but several percent of the ARM were randomized in peak alternating fields of $600 \mathrm{Oe} ; 50 \%$ of ARM coercivities were apparently less than $160-210$ Oe, the lower values occurring deep in each core. The af demagnetization characteristics of SIRM were in many respects similar to those of ARM. Clearly, very high coercivity magnetic particles were not abundant in these specimens.

The spectrum of coercivities carrying the NRM differed greatly with depth in core. In the upper more stable sections of the cores the NRM coercivity spectrum was, in general, similar to the total coercivity spectrum deduced from the ARM demagnetization curve. The af demagnetization curve of the NRM from the unstable section of the core, on the other hand, was more similar to that of the VRM. Although a stable component of NRM may be present, it was dominated by a viscous remanence that presented insuperable demagnetization and measurement difficulties.

Remanent hysteresis curves were determined for each of the specimens by means of a solenoid for fields up to $600 \mathrm{Oe}$ and an electromagnet for higher fields. The curves of IRM showed

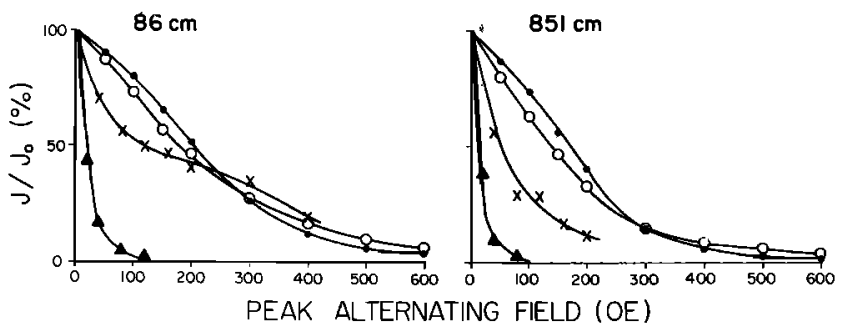

Fig. 9. Alternating field demagnetization characteristics of four types of remanent magnetization in each of two specimens from core V20-102. The VRM (solid triangles) is that produced in a 1.0-Oe field in 1000 hours; ARM (solid circles) was produced in a 2000-Oe alternating field with a 0.5 -Oe bias field; SIRM (dotted circles) was produced in a $2000-O e$ direct field. The NRM is represented by crosses.

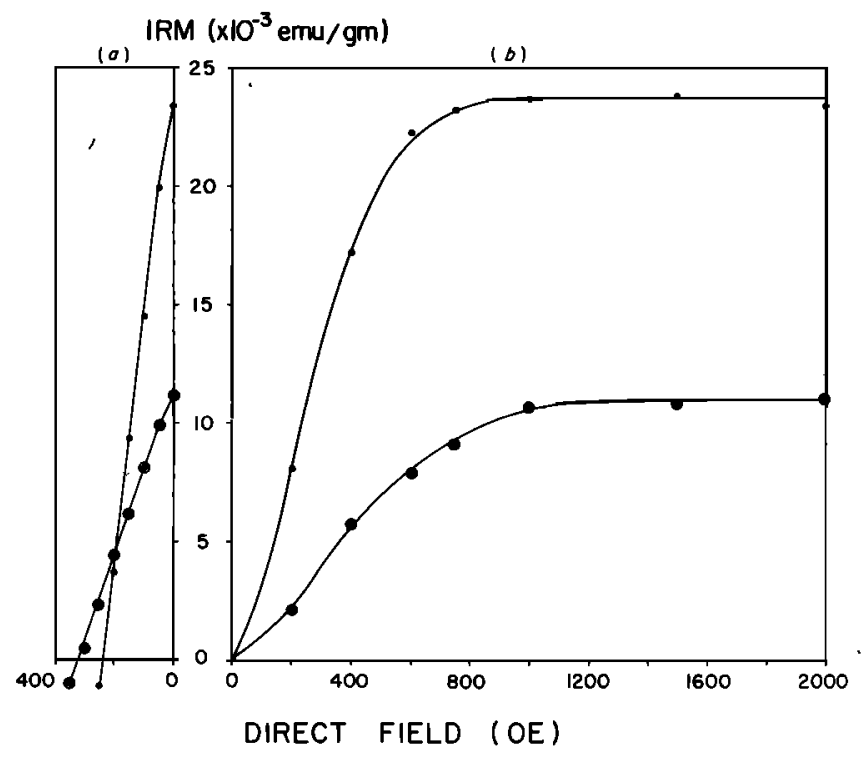

Fig. 10. Remanent hysteresis characteristics of two specimens from core RC10-158: $220 \mathrm{~cm}$ (dotted circles) and $810 \mathrm{~cm}$ (solid circles). (a) Decrease in IRM with progressively higher opposing fields; the opposing field necessary to reduce the SIRM to zero. is the remanent coercivity $H_{c r}$. (b) Acquisition of IRM with application of progressively higher direct fields. A direct field of $800-1200$ Oe is sufficient to produce a maximum IRM in either specimen.

that maximum values of IRM were attained in fields of less than 1200 Oe (Figure 10), this finding indicating again that large concentrations of high-coercivity minerals (such as hematite) were not present in these cores. The SIRM increased in magnitude with depth in each core and was accompanied by a proportionate increase in susceptibility $k$. This reflects an increase in concentration of the magnetic mineral. However, the reverse field required to reduce the SIRM to zero (remanent coercivity $H_{c r}$ ) decreased with depth, and an increase in the low-coercivity fraction is again indicated (Table 3). The unstable sections of the cores appear to be characterized by remanent coercivities less than about $275 \mathrm{Oe}$.

TABLE 3. Remanent Hysteresis Parameters of Five Specimens Fron Each of Three Cores

\begin{tabular}{lcccc}
\hline Core & $\begin{array}{c}\text { Depth in } \\
\text { Core, cm }\end{array}$ & $\begin{array}{c}k, * \\
\times 10^{-6} / \mathrm{g}\end{array}$ & $\begin{array}{c}\text { SIRM, } \\
\times 10^{-3} \text { emu/g }\end{array}$ & $\begin{array}{c}H_{\text {crs, } 5} \\
\text { Oe }\end{array}$ \\
\hline V20-98 & 162 & 39.1 & 6.01 & 347 \\
& 442 & 44.2 & 7.35 & 296 \\
& 575 & 57.2 & 10.53 & 276 \\
V20-102 & 612 & 56.2 & 10.49 & 274 \\
& 852 & 128.5 & 22.78 & 261 \\
& 86 & 39.4 & 7.19 & 385 \\
& 253 & 37.8 & 5.97 & 328 \\
RC10-158 & 543 & 55.6 & 8.98 & 271 \\
& 701 & 55.2 & 7.81 & 267 \\
& 851 & 75.5 & 12.28 & 250 \\
& 100 & 58.2 & 11.10 & 361 \\
& 220 & 67.1 & 11.21 & 317 \\
& 420 & 92.7 & 13.73 & 270 \\
& 625 & 137.5 & 23.72 & 234 \\
& 810 & 140.5 & 23.41 & 238 \\
\hline
\end{tabular}

*Initial susceptibility.

+Maximum or saturation isothermal remanence (SIRM) was attained in fields of about $1200 \mathrm{Oe}$.

SOpposing field necessary to reduce SIRM to zero (remanent coercivity). 


\section{Magnetic Mineralogy}

Extraction of magnetic minerals. In order to identify the magnetic minerals responsible for the observed magnetization properties of these sediments, the most highly magnetic minerals were extracted from the sediment by a technique similar to that described by L $\phi v l i e$ et al. [1971]. Several tens of grams of sediment were simply allowed to disaggregate in distilled water with the aid of a sonifier. This dilute suspension was repeatedly passed in a slow flow of water through a narrow tube near the pole pieces of a Franz electromagnetic separator until no further magnetic particles were being extracted. Although sufficient quantities of the magnetic minerals were extracted for our purposes, a comparison of susceptibility and SIRM measurements on the sediment before and after the extraction procedure indicated that only several percent of the magnetic minerals originally present were being obtained. A similar, though less severe, problem was encountered by Lovlie et al. [1971].

Thermomagnetic analysis. Thermomagnetic analysis was performed on a portion of each extract with a Curie balance incorporating a vertical suspension, a sensitive electrobalance, and a $10-\mathrm{cm}$ electromagnet with special pole pieces and having the capability of continuously recording the change of magnetization with changing temperature on an $X$ - $\gamma$ recorder. The equipment was not calibrated for absolute magnetization measurements, and so no measurements of saturation magnetizations were obtained. Temperature determinations were made with an accuracy of $\pm 5^{\circ} \mathrm{C}$. Magnetic fields of 3000 Oe were used to obtain the thermomagnetic curves, and measurements were made at intervals in zero magnetic field to check possible weight loss of the samples.

The high-field thermomagnetic curve of each of the fifteen magnetic extracts studied was irreversible; the magnetization after thermal cycling was always less than the initial room temperature value (Figure 11). In the samples from near the tops of the cores two magnetic mineral phases were distinguished in the heating curves with apparent Curie temperatures of about $360^{\circ}$ and $570^{\circ} \mathrm{C}$. However, the kink in the heating curve corresponding to the $360^{\circ} \mathrm{C}$ phase became less pronounced below about a 3-m depth in each core and appeared to be almost absent in the lowermost samples. Only the high Curie temperature phase was present in the cooling curves of all samples. The Curie temperature data are summarized in Figure 12.

$X$ ray diffraction analysis. Another source of information on the identity of the strongly magnetic minerals in the extracts was obtained by $X$ ray diffraction analysis using a Siemans diffractometer with a CuK $\alpha$ radiation, a scintilla-

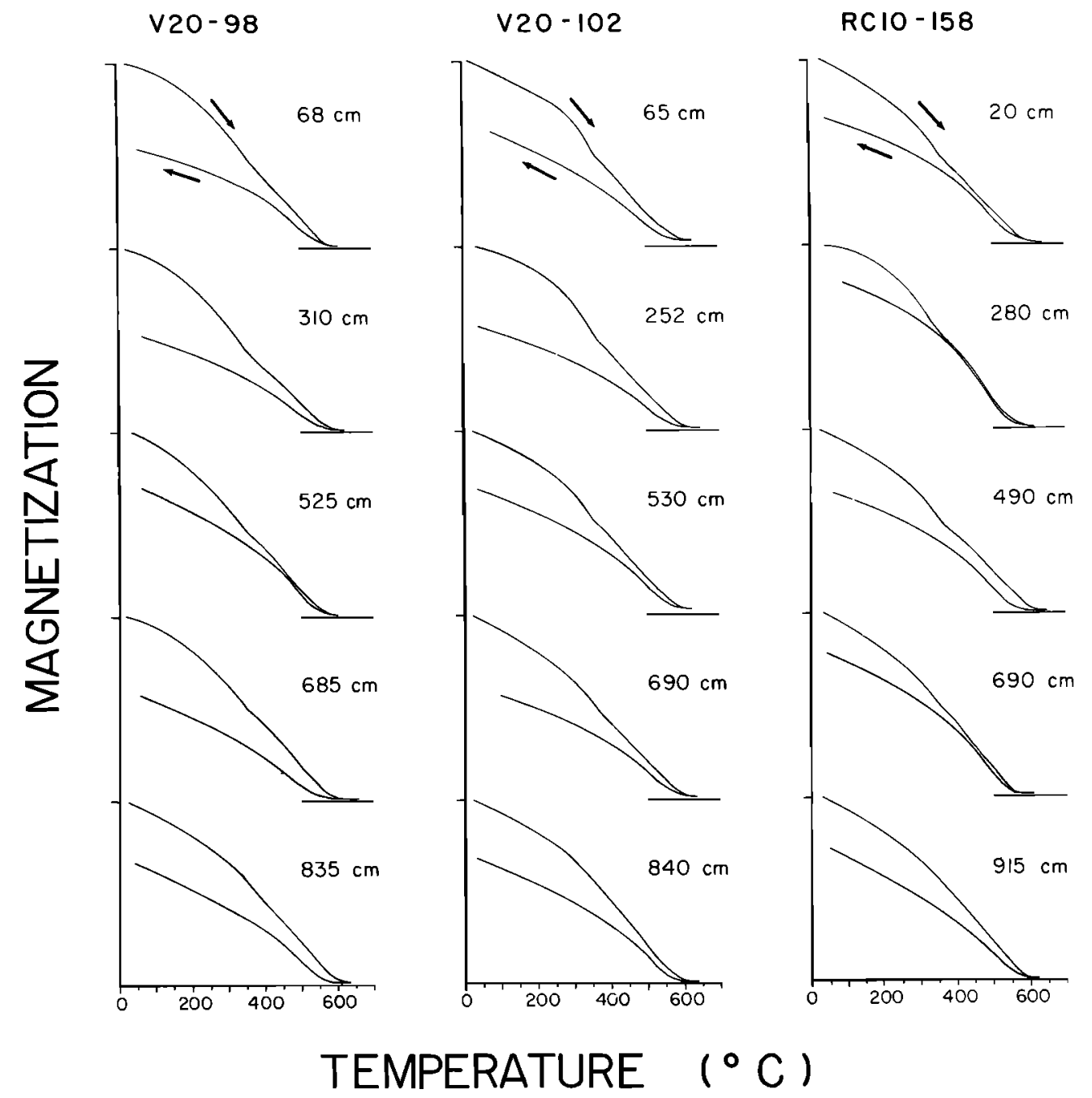

Fig. 11. Thermomagnetic curves of magnetic extracts from three cores. Measurements were performed in air with a 3000-Oe field. Heating and cooling curves are in the same relative sense for each extract as those indicated by arrows. 


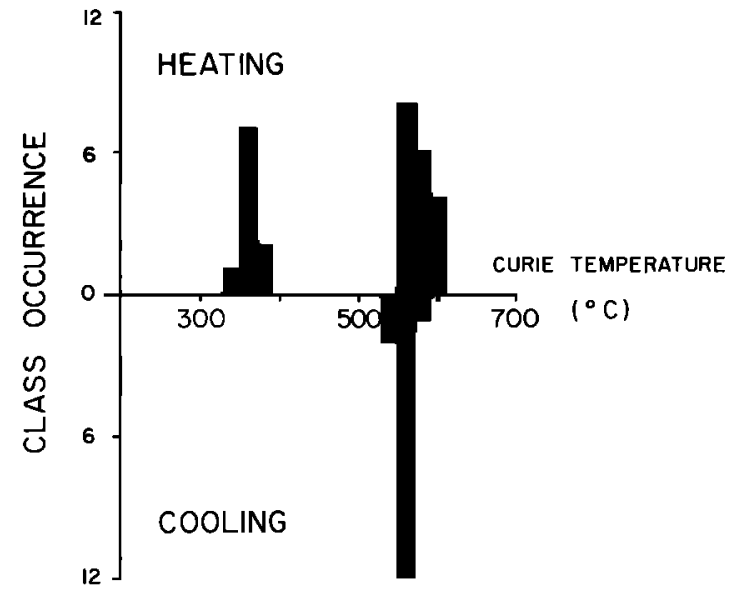

Fig. 12. Apparent Curie temperatures determined from the heating and cooling thermomagnetic curves of 15 magnetic extracts shown in Figure 11.

tion detector, a $1 / 2 \%$ min scan speed, and a $1 \% /$ in. chart speed. A graphite focusing monochromator was used to filter out background noise due to the fluorescence of iron in the samples. Because of the fine grain size, only a minimum of dry grinding with an agate mortar and pestle was necessary on each powder specimen to achieve a nonoriented powder mount.

Quartz, plagioclase feldspars, and chlorite were the principal nonferrimagnetic minerals identified in each magnetic extract, although their diffraction peaks were generally of lower intensity with depth in core. These minerals may be present in the magnetic extracts as contaminants, especially in the case of chlorite, or because some ferrimagnetic minerals may occur as inclusions, which are found elsewhere in feldspars [Hargraves and Young, 1969]. A spinel-structured mineral was identified in each sample. The lattice parameter of the mineral was calculated by taking a simple average of the cubic cell size determined from four to five diffraction peaks ([220], [311], [422], [333], and [440]). The calculated lattice parameter of the spinel mineral varied from 8.37 to $8.34 \AA$; these values are plotted in Figure 13 against the depth in core of each sample and compared with the lattice parameter calculated from an $X$ ray diffraction analysis of nearly pure magnetite from Essex county, New York, and the range of lattice parameters reported for maghemite [Basta, 1959]. Diffraction peaks of hematite were looked for but were not identified in any of the samples.

A solid-solution series has been shown to exist between magnetite and maghemite as end members with a continuous decrease in the lattice parameter with degree of oxidation of magnetite to maghemite [Basta, 1959; O'Reilly and Readman. 1971]. The lattice parameter for the spinel mineral observed here would suggest a composition between that of magnetite and that of maghemite in the upper sections of the cores and a composition close to that of maghemite in the lower sections. However, in samples from the upper core sections, small subsidiary reflections, which had a lattice parameter $(8.39 \AA)$ near to that of stoichiometric magnetite, often occurred. These reflections were especially evident on the high Bragg angle reflections. Several of the reflections, particularly the [311], also changed in shape from broad peaks to ones that were more peaked, with increasing depth in each core. The broader peaks are interpreted as due in part to interference from stoichiometric magnetite and in some cases from the appropriate chlorite peaks. The [111] reflection was not detected with certainty in any of the samples.

Energy dispersive analysis of $X$ radiation. Because highly oxidized titanomagnetites of various compositional parameters are difficult to distinguish by $\mathrm{X}$ ray analysis alone [O'Reilly and Readman, 1971], a semiquantitative determination of the $\mathrm{Ti}: \mathrm{Fe}$ ratio in the magnetic extracts was made with an energy dispersive analysis of $X$ rays (EDAX) apparatus attached to a scanning electron microscope. Specimen powders were mounted on carbon stubs with double-stick cellophane tape and coated with carbon in an evaporator. The Ti: Fe ratio was determined by analyzing many separate grains at high magnification and by averaging over many grains at lower magnification.

When an analysis was made averaging over many grains at low magnification, several elements were detected. The aluminum, silicon, calcium, and sodium observed correspond to the quartz and feldspars identified by $X$ ray diffraction analysis. Some of the iron observed undoubtedly is incorporated in chlorite. The relative peak heights of titanium and iron suggested a $\mathrm{Ti}: \mathrm{Fe}$ ratio of about $1: 4$. However, analysis of individual grains at high magnification indicated that two types of nonsilicate grains were present. One type was iron rich with a titanium peak always less than $5 \%$ of that of iron. If the observed proportion of iron to titanium were present in a magnetite lattice, the compositional parameter $x$ in the

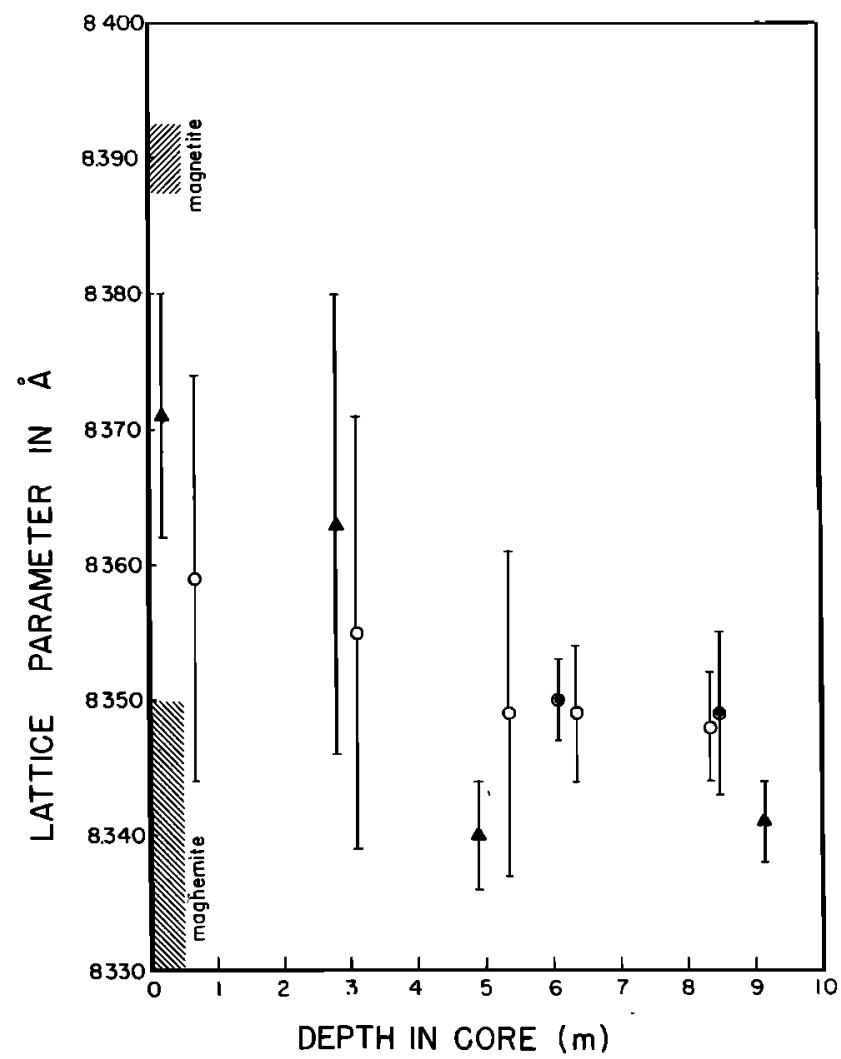

Fig. 13. Variation of lattice parameter of spinel mineral with depth in three cores: V20-98 (open circles), V20-102 (dotted circles), and RC10-58 (solid triangles). Bars define standard error for each determination. Range of lattice parameters for maghemite is from Basta [1959]; lattice parameter of magnetite is from a measurement of magnetite from Essex county, New York, which agrees, within the error, with the lattice parameter calculated from the same first eight $d$ spacings on ASTM card 11-614 for magnetite. 
general titanomagnetite formula $\left(\mathrm{Fe}_{3-x} \mathrm{Ti}_{x} \mathrm{O}_{4}\right)$ would be less than 0.15 . The other type appeared to have as much titanium as iron and may represent grains of ilmenite that are paramagnetic at room temperature.

There was no discernible variation in the $\mathrm{Ti}: \mathrm{Fe}$ ratio in extracts from different depths in core. However, the impure nature of the magnetic extracts and the difficulty in determining the compositions of the finest grains prohibited a more detailed description. It is possible that titanomagnetites with high values of the compositional parameter may be present in the finest size range, which we were unable to analyze. On the other hand, several large grains with high titanium contents would account for the observed average $\mathrm{Ti}$ : Fe ratio of the extracts.

Discussion of magnetic mineralogy data. Readman and $O^{\prime}$ Reilly [1970] observed that the inversion of a fine-grained highly oxidized magnetite in their thermomagnetic analysis (performed with the sample in vacuum) was evident as a drop in magnetization occurring between $350^{\circ}$ and $400^{\circ} \mathrm{C}$. The inversion products were magnetite and hematite. The apparent Curie temperature of $360^{\circ} \mathrm{C}$ observed in our thermomagnetic heating curves, in light of the $\mathrm{X}$ ray results, can then be interpreted as a decrease in magnetization resulting from the inversion of an oxidized magnetite. The $570^{\circ} \mathrm{C}$ Curie temperature phase is due to magnetite that was probably present initially and may also originate as a product of the inversion. However, the drop in magnetization at about $360^{\circ} \mathrm{C}$ in the thermomagnetic curves that would correspond to the inversion became less distinct with samples from greater depths in core, even though a more highly oxidized magnetite was indicated in the $X$ ray data. This apparent contradiction between $X$ ray and thermomagnetic data for the lowermost samples is difficult to reconcile.

The thermomagnetic behavior of a highly oxidized titanomagnetite with a low compositional parameter such as may be present here would be in many respects similar to that of a highly oxidized pure magnetite, since the presence of titanium does not appear to have a stabilizing effect [ $O$ 'Reilly and Readman, 1971]. Small differences in titanium content should not alter the temperature of inversion but only change the relative proportions of the inversion products. For oxidized titanomagnetites with compositional parameters initially less than about 0.4 , the inversion is always characterized by a decrease in magnetization [Readman and $O$ 'Reilly. 1970], although the inversion products, or at least their relative proportions, are expected to be somewhat different from those reported by Readman and O'Reilly because our analyses were performed in air, oxidation thus being allowed to occur readily. The temperature of inversion may depend on some other physical characteristics of the sample, such as the presence of other impurities [Pouillard, 1950], that we were not able to discern.

It is possible that maghemite may be present in materially important amounts in the magnetic extracts from deep in each core and therefore may be readily identified by $\mathrm{X}$ ray analysis, whereas magnetite may be present in concentrations just sufficient to be magnetically dominant in the thermomagnetic curves. Small concentrations of magnetite, if they are included in nonferrimagnetic grains, might not be oriented by the ambient geomagnetic field to contribute to NRM and would be difficult to identify by $X$ ray. Some of the maghemite grains may also be superparamagnetic, as will be discussed below. This interpretation is consistent with the thermal demagnetization curves of NRM and a strong-field
IRM of adjacent specimens from the magnetically unstable section of core V20-102 (Figure 6). The NRM was dominated by a low blocking temperature component, which we believe is carried by the maghemite but which did not contribute substantially to the IRM. The thermal demagnetization of the strong-field IRM is in some respects analogous to the strongfield thermomagnetic curves, both of which indicate a dominant high blocking temperature or Curie temperature mineral indicative of magnetite. The increase in magnetic viscosity and the decrease in lattice parameter of the magnetic mineral with depth in each core suggest that the maghemite is the carrier of viscous remanence. A stable NRM in the upper levels of the cores is probably carried by essentially unoxidized magnetite.

Dickson and Foster [1966] identified hematite in two samples from a core in this region on the basis of rather poorly defined thermomagnetic curves. They suggested that hematite, in a superparamagnetic state, was at least in part responsible for the observed unstable magnetic behavior of their core. Creer's [1957] study of the unstable Keuper marls indicated that very fine grained hematite, which may have been present in the marls as a cementing agent, can indeed be a carrier of viscous remanence and could account for magnetically unstable behavior. But subsequent study has shown that the secondary component of magnetization of the marls required peak alternating fields of about 600 Oe to destroy it [Creer. 1959]. A VRM acquired only over a very short period of time by some hematite-bearing rocks had also been found to be very resistant to alternating fields, destructive fields of over 1000 Oe being required [Biquand and Prevot, 1971]. The low stabilities against alternating fields of the NRM in Dickson and Foster's core, as well as those for both the NRM and the VRM in the cores investigated here, exclude hematite as a significant remanence carrier in these sediments. This conclusion is supported by the lack of evidence for hematite in our thermomagnetic and $X$ ray investigations of the magnetic extracts.

Magnetic grain size. An estimate of the magnetic grain size present in the sediment may be gained from inspection of micrographs taken with a scanning electron microscope (Figure 14). Only a small number of particles in each sample approached $20 \mu \mathrm{m}$ in diameter, and most were finer than 0.5 $\mu \mathrm{m}$ in diameter, a result similar to that found by $L \phi v l i e$ et al. [1971] in other deep-sea cores. No euhedral grains were observed. The smaller grains $(<1 \mu \mathrm{m})$ were generally subrounded, and the largest grains observed were often angular (Figure 14). Many of the grains appeared to be approximately equidimensional in the plane of the photos or to have elongation ratios less than $2: 1$, although some grains with elongation ratios as high as 5:1 were present in each sample.

The grain sizes observed here are not necessarily representative of the grain size distribution of the magnetic minerals in the extracts because some ferrimagnetic grains may be included in larger paramagnetic or diamagnetic grains [Evans and Wayman, 1970; Hargraves and Young, 1969]. In addition, nonferrimagnetic mineral particles may be present as contaminants due to inadequacies of the extraction procedure. Our $\mathrm{X}$ ray data show that both may be possibilities in these extracts. It is safe to say, however, that the true magnetic particle sizes would be, if anything, smaller on average than the observed particle sizes. Although only several percent of the magnetic particles in the sediment were apparently removed, it is probably the ultrafine magnetic grains that escaped extraction, perhaps through association with nonferrimagnetic 

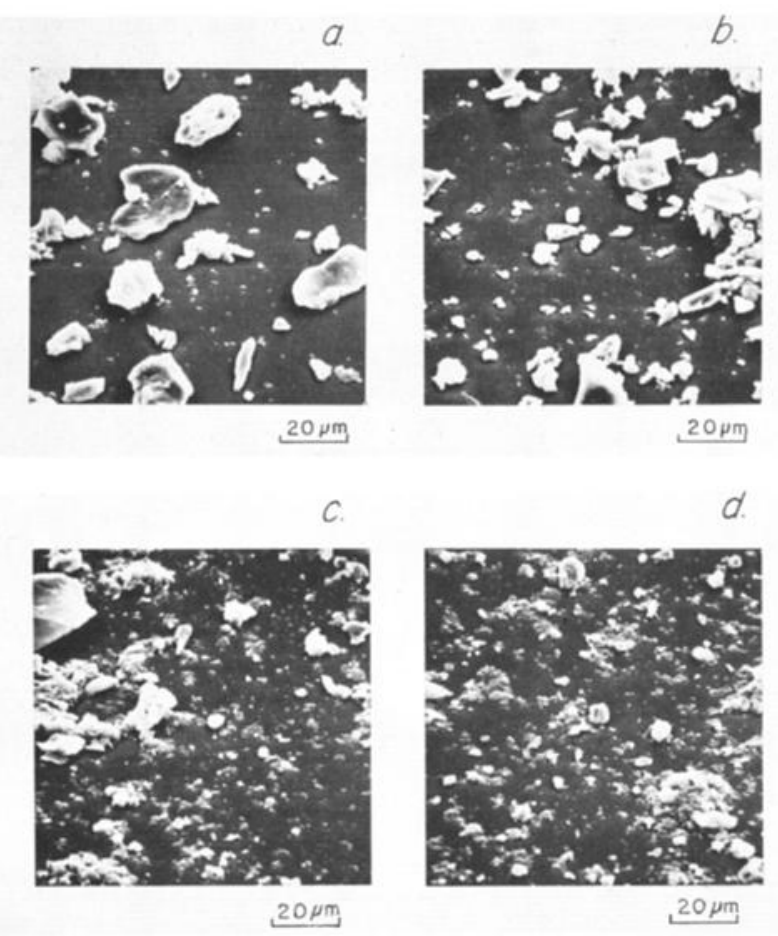

Fig. 14. Scanning electron microphotographs of magnetic extracts. (a) $65 \mathrm{~cm}$. (b) $840 \mathrm{~cm}$ in V20-102. (c) $490 \mathrm{~cm}$. (d) $915 \mathrm{~cm}$ in RC10-158. Scale is shown.

grains. The small mean grain size of the total sediment (usually less than $1 \mu \mathrm{m}$ in the cores) is in accord with the magnetic grain size estimates.

On the basis of the direct observations of the magnetic grain sizes there would appear to be no significant amounts of true multidomain (MD) magnetic grains present, if it is assumed that true MD behavior in the case of magnetite begins at grain diameters greater than about $17 \mu \mathrm{m}$ [Stacey, 1963; Everitt, 1962]. Most of the observed grains were in the size range of pseudo single-domain (PSD) behavior in magnetite (approximately 0.06-17 $\mu \mathrm{m}$ [Stacey, 1963]). As we were not able to establish a lower size limit for the magnetic grains, it is not known to what extent single-domain (SD) grains (of the order of 0.03-0.06 $\mu \mathrm{m}$ for magnetite) are present. A large number of particles as small as $0.1 \mu \mathrm{m}$ were observed in each sample, so that it is reasonable to assume that finer particles are also present, perhaps even into the superparamagnetic size range.

\section{Discussion}

The unstable magnetic behavior of the lower section of the cores is related to the presence of a highly oxidized magnetite similar in structure to that of maghemite. This mineral may have formed by low-temperature oxidation of detrital magnetite. The phenomenon of low-temperature oxidation has been found to be quite common in titanomagnetites in deep-sea basalts [Ozima and Larson, 1970; Ozima and Ozima. 1971; Lowrie et al., 1973]. It is quite likely that a similar process can occur in deep-sea sediments. However, the only previous report of similar magnetic mineralogy was by Harrison and Peterson [1965], who identified a magnetic mineral intermediate in composition between magnetite and maghemite in a deep-sea sediment core from the Indian Ocean. No magnetic remanence data were presented, and so it is not known whether the mineral that they identified was also associated with unstable magnetization.

The low-temperature oxidation of titanomagnetites is accompanied by a decrease in saturation magnetization and in the magnetocrystalline anisotropy [Readman and O'Reilly, 1972], which may result in the production of magnetically unstable particles from those that were stable in the unoxidized state. For example, the critical diameter of stoichiometric magnetite grains at the room temperature superparamagnetic threshold (relaxation time $10^{2} \mathrm{~s}$ ) is about $0.03 \mu \mathrm{m}$ [Néel, 1949; Dunlop, 1973] and is relatively insensitive to elongation of the grains; a particle length of $0.03-0.05 \mu \mathrm{m}$ defines the superparamagnetic threshold size over a range of prolate spheroid axial ratios from equidimensional to more than $5: 1$ [Evans and McElhinny, 1969]. However, Readman and $O^{\prime}$ Reilly [1972] have calculated the room temperature superparamagnetic threshold diameter of highly oxidized magnetite to be about $0.12 \mu \mathrm{m}$. Thus grains of magnetite with diameters of less than $0.12 \mu \mathrm{m}$ will be normally stable SD or PSD but will become superparamagnetic if they are highly oxidized. The critical diameter for the SD-MD transition in magnetite decreases from about 0.056 to $0.023 \mu \mathrm{m}$ with oxidation [Readman and $O^{\prime}$ Reilly, 1972]. Since highly oxidized magnetite grains less than $0.12 \mu \mathrm{m}$ are superparamagnetic, there is the possibility that no stable SD size region can exist in highly oxidized magnetites, although a limited PSD region is not necessarily excluded. A similar phenomenon would occur as a result of the oxidation of titanium-bearing magnetites [Readman and O'Reilly, 1972; Butler, 1973].

In a given oxidizing environment the finest-sized grains would be oxidized most readily, since specific surface area plays a predominant role in the kinetics of the oxidation [Colombo et al., 1968; Gallagher et al., 1968]. However, very fine magnetite grains, which might be stable SD or PSD, may carry a substantial portion of the stable NRM that is thought to be acquired in deep-sea sediments by postdepositional interstitial grain rotations [Kent, 1973]. The low-temperature oxidation of the finest of these grains would substantially reduce the NRM intensity, since the products of the oxidation may be superparamagnetic or nearly so. If the grain size of some of the oxidation products is not below the superparamagnetic threshold but allows them to have relaxation times of the order of months or years, it is possible for these grains to contribute toward a secondary component of magnetization such as VRM, as appears to have occurred to a large extent in the lower section of the cores from the central North Pacific. A chemical remanent magnetization (CRM) may also be acquired as a result of oxidation occurring in the geomagnetic field. However, it has been observed in laboratory experiments that such a CRM is generally of weak intensity and low magnetic stability, at least for pure magnetite [Johnson and Merrill. 1972], and could possibly be difficult to distinguish from VRM.

The extent to which in situ low-temperature oxidation of magnetite can occur in sediments is also dependent on the availability of oxygen and the time constant for the reaction. The source of significant amounts of oxygen in the ocean bottom environment is contained in the bottom waters. Generally, deep-sea sediments become effectively isolated from this source after burial to some depth, and any oxygen remaining is rapidly used in the oxidation of organic matter. Consequently, the redox state of the sediment is mainly determined by the duration of contact with the oxidizing bottom waters [Bramlette, 1961; Arrhenius, 1963]. It would then seem 
unlikely that significant oxidation of magnetite can proceed at depth in the sediment column but must rather occur near the sediment-water interface. That the oxidation in these cores is not significantly postdepositional is suggested by better correlation of the stable/unstable magnetic boundary with age than with depth.

If the oxidation process can occur only near the sedimentwater interface, the rate of the oxidation reaction must be rapid enough that the oxidation of the magnetite grains can occur before their effective burial and isolation from the source of oxygen. By extrapolating from laboratory results Readman and $O^{\prime}$ Reilly [1970] suggested a time constant of about $10^{6}$ years for low-temperature oxidation of titanomagnetites at room temperature. However, a shorter time constant for the oxidation process was suggested by work on dredged basalts. The large decrease in remanent magnetization of basalts with distance from the median valley of the mid-Atlantic ridge is thought to be due to the lowtemperature oxidation of titanomagnetites with time [Irving. 1970]. Most of the remanent intensity decrease occurred within only $6 \mathrm{~km}$ of this median valley, which, at a half spreading rate of $2 \mathrm{~cm} / \mathrm{yr}$, would be within only 300,000 years [Irving et al., 1970]. When the dependence of the reaction rate on grain size and other characteristics of the initial material (e.g., crystal perfection and perhaps the presence of water [Elder, 1965]) are considered, it appears likely that significant low-temperature oxidation can proceed in naturally occurring magnetite or titanomagnetite grains over a range of time constants, some of which may be considerably shorter than the $10^{8}$ years suggested by Readman and $O^{\prime}$ Reilly [1970]. The interpretation of the intensity decrease in the dredged basalts would suggest a time constant as short as about $10^{6}$ years in the deep-ocean environment.

The low rates of sedimentation in this area would allow particles at the sediment-water interface to be exposed to the oxygenated bottom waters for some length of time. This exposure would be considerably lengthened by bioturbation (for which some evidence is present in these cores) if it results in a thoroughly mixed layer near the sediment surface. For example, for a mixed layer thickness of $5-10 \mathrm{~cm}$ [Ruddiman and Glover, 1972] and a sedimentation rate of $1 \mathrm{~mm} / 1000 \mathrm{yr}$, any particle deposited will have access to the oxygenated bottom waters for a period of time from 50,000 to 100,000 years before effective burial. Significant oxidation may occur over this time range. An increase in sedimentation rate would decrease the exposure time for the sediment.

It is also possible that some maghemite was formed prior to deposition. For example, oxidation of magnetite grains may occur in the water column before they are incorporated in the sediment. A simple Stokes' law calculation shows that the time required for a SD spherical magnetite particle $0.03 \mu \mathrm{m}$ in diameter to settle through a $5200-\mathrm{m}$ still-water column is about 120,000 years. Oxidation during settling might be expected to be most pronounced in the finest grains because the time spent in the oxygenated water column varies inversely with the square of the particle diameter. Oxidation of particles in the water column would also be cumulative with that occurring near the sediment surface.

It is apparent that a variety of sedimentological and geochemical factors may be responsible for the change in degree of oxidation and the range of magnetically stable grain sizes that we believe to be the explanation of the change in magnetic properties of these sediment cores with time. These factors are in turn controlled by changes in the environment.
The bimodal age distribution of the magnetic instability termination levels and, in . particular, the $3.0-\mathrm{m} . \mathrm{y}$. mean age (Figure 3) seem to be related to established climatic events of global and regional extent. The 3.0-m.y. mean age may correspond to the onset of late Tertiary climatic deterioration as determined in the equatorial Pacific (3.0 m.y. [Jacobs and Hays, 1972]), North Atlantic (3.0 m.y. [Laughton et al., 1970]), Iceland (3.0 m.y. [McDougall and Wensink, 1966]), and in the Sierra Nevada (2.7-3.1 m.y. [Curry, 1966]), whereas the younger mean age ( 1.5 m.y.) may reflect the effects of the initiation of mid-latitude Pleistocene glaciations as evidenced, for example, by increased ice rafting of detritus 1.2 m.y. ago in the North Pacific [Kent et al., 1971]. There probably was an increase in the rate of deposition in the central North Pacific area associated with the change of climatic conditions, but we cannot document it in our cores because of the lack of stratigraphic time control below the termination levels. However, a similar sediment sequence was recovered from three sites (37, 38, and 39) during leg 5 of the Deep-Sea Drilling Project (DSDP) in this area of the central North Pacific.

Three lithologic units were recognized at each site: a thin basal amorphous iron-manganese oxide facies containing nannofossils of lower Oligocene to lower Eocene age; an intermediate red clay facies, barren of fossils, between 14 and 28 $\mathrm{m}$ thick; and an upper red clay unit, 3-11 $\mathrm{m}$ thick, that is lighter in color and contains glacial Pleistocene detritus [McManus et al., 1970]. The upper unit apparently corresponds to the section in our cores that is magnetically stable; the lower magnetically unstable sections of our cores correspond to the upper part of the intermediate red clay facies. Rates of sedimentation of the upper unit identified in the DSDP cores range from 1.5 to $5.5 \mathrm{~mm} / 1000 \mathrm{yr}$, similar to the rates calculated for the upper parts of our three cores, whereas the rates for the intermediate unit are apparently only 0.3 to $0.8 \mathrm{~mm} / 1000 \mathrm{yr}$ [McManus et al., 1970], which allow longer times for maghemitization. There also appears to be some increase in sedimentation rates within the stable sections of the cores examined here (Table 1).

The termination of instability in central North Pacific red clay piston cores was associated as well with a sediment color change and a decrease in manganese micronodule concentration [Opdyke and Foster, 1970]. The color change was also observed in DSDP cores from the same region. It distinguished the intermediate from the upper red clay facies and was due to a relative decrease in amorphous iron-manganese oxides and an increase in detrital materials of probable eolian origin [von der Borch and Rex, 1970]. The increased detrital input and sedimentation rate, accompanied by a perhaps related change from the more oxidizing environment that produced the manganese micronodules, would result in an increase in the unoxidized fraction of magnetic grains available to carry a stable remanence.

Our explanation for the magnetic instability in red clay sediments is dependent on the correct identification of the mineral responsible for the unstable NRM as maghemite and its mode of formation. In this respect the apparent discrepancy between thermomagnetic and $X$ ray data for the samples at depth, and also the change in the character of the thermomagnetic (heating) curves with depth in each core, may require a fuller investigation, which is beyond the scope of this paper. A perhaps related problem is whether the magnetic extract was representative of the magnetic mineralogy of the sediment, since apparently only several percent of the total 
was obtained with our technique. However, the similarity between the thermomagnetic curve for the extract and the thermal demagnetization curve of a saturation IRM involving the entire magnetic mineralogy of the sediment would argue that information gained from the extracts is not atypical.

If it is assumed that maghemite is responsible for the unstable magnetic behavior, other explanations for its formation cannot be summarily dismissed. For example, some of the maghemite may have formed authigenically, perhaps related to the occurrence of the amorphous iron-manganese oxides, and not as a result of oxidation of detrital magnetite. This possibility is suggested by the decrease in saturation remanence from the unstable to the stable sections of the cores; an increase in saturation remanence would have been expected owing to increased detrital input. Authigenic formation of maghemite and low-temperature oxidation of original magnetite may both occur under similar highly oxidizing conditions, so that their relative contribution may be difficult to establish. The absence of a substantial stable component of NRM in the lower sections of the cores, in spite of the thermomagnetic evidence for the presence of magnetite, suggests that at least some of the maghemite detected was produced by low-temperature oxidation of magnetite grains that were originally contributing to the NRM. It will be interesting to see if similar effects are associated with very slowly deposited sediment of different lithology and from different areas of the world ocean.

Acknowledgments. We wish to thank N. D. Opdyke and W. L. Donn for critical review of the manuscript. Access to an $\mathrm{X}$ ray diffractometer and the EDAX apparatus was provided by P. E. Biscaye, and his assistance, as well as that of Paula Varlamoff, is greatly appreciated. We also thank R. F. Butler for kindly supplying us with a preprint of his simulating paper. The anonymous Journal reviewers must also be thanked for their constructive comments, which improved the paper. This research was supported by the National Science Foundation under grants GA $30569 \mathrm{X}$ and GA 36190 . Contribution 2103, Lamont-Doherty Geological Observatory.

\section{REFERENCES}

Arrhenius, G., Pelagic sediments, in The Sea, vol. 3, edited by M. N. Hill, pp. 655-727, Interscience, New York, 1963.

Basta, E. Z., Some mineralogical relationships in the system $\mathrm{Fe}_{2} \mathrm{O}_{3}-\mathrm{Fe}_{3} \mathrm{O}_{4}$ and the composition of titanomaghemite, Econ. Geol. $54,698-719,1959$.

Biquand, D., and M. Prevot, A. F. demagnetization of viscous remanent magnetization in rocks, $Z$. Geophys., 37, 471-485, 1971.

Bramlette, M. N., Pelagic sediments, in Oceanography. Publ. 67. edited by M. Sears, pp. 345-366, American Association for the Advancement of Science, Washington, D. C., 1961.

Butler, R. F., Stable single-domain to superparamagnetic transition during low-temperature oxidation of oceanic basalts, J. Geophys. Res., 78, 6868-6876, 1973.

Colombo, U., G. Fagherazzi, F. Gazzarrini, G. Lanzauecchia, and G. Sironi, Mechanism of low temperature oxidation of magnetites, Nature, 219, 1036-1037, 1968.

Creer, K. M., The remanent magnetization of unstable Keuper marls, Phil. Trans. Roy. Soc. London. Ser. A., 250, 130-143, 1957.

Creer, K. M., A. C. demagnetization of unstable Triassic Keuper marls from S. W. England, Geophys. J., 2, 261-275, 1959.

Curry, R. R., Glaciation about 3,000,000 years ago in Sierra Nevada, Science, $154,770-771,1966$.

Dalrymple, G. B., Potassium-argon dating of geomagnetic reversals and North American glaciations, in Calibration of Hominoid Evolution, edited by W. W. Bishop and J. A. Miller, pp. 107-134, Scottish Academic Press, Edinburgh, 1972.

Dickson, G. O., and J. Foster, Magnetic stratigraphy of a deep-sea core from the North Pacific Ocean, Earth Planet. Sci. Lett., I, $458-462,1966$.

Dunlop, D. J., Superparamagnetic and single-domain threshold sizes in magnetite, J. Geophys. Res., 78, 1780-1793, 1973.
Elder, T., Particle size effect in oxidation of natural magnetite, $J$. Appl. Phys., 36, 1012-1013, 1965.

Evans, M. E., and M. W. McElhinny, An investigation of the origin of stable remanence in magnetite-bearing igneous rocks, $J$. Geomagn. Geoelec., 2l, 757-773, 1969.

Evans, M. E., and M. L. Wayman, An investigation of small magnetic particles by means of electron microscopy, Earth Planet. Sci. Lett., 9. 365-370, 1970 .

Everitt, C. W. F., Thermoremanent magnetization, 3, Theory of multidomain grains, Phil. Mag., 7, 599-616, 1962.

Ewing, J., M. Ewing, T. Aitken, and W. J. Ludwig, North Pacific sediment layers measured by seismic profiling, in The Crust and Upper Mantle of the Pacific Area, Geophys. Monogr. Ser., vol. 12, edited by L. Knopoff, C. L. Drake, and P. J. Hart, pp. 147-173, AGU, Washington, D. C., 1968.

Fleming, R. H., General features of the oceans, Geol. Soc. Amer. Mem. 67, 87-107, 1957.

Foster, J. H., A paleomagnetic spinner magnetometer using a fluxgate gradiometer, Earth Planet. Sci. Lett., l, 463-466, 1966.

Gallagher, K. J., W. Feitknecht, and U. Mannweiler, Mechanism of oxidation of magnetite to $\gamma-\mathrm{Fe}_{2} \mathrm{O}_{3}$, Nature, 217, 1118-1121, 1968.

Hargraves, R. B., and W. M. Young, Source of stable remanent magnetism in Lambertville diabase, Amer. J. Sci., 267, 1161-1177, 1969.

Harrison, C. G. A., and M. N. A. Peterson, A magnetic mineral from the Indian Ocean, Amer. Mineral., 50, 704-712, 1965.

Horn, D. R., B. M. Horn, and M. N. Delach, Sonic properties of deep-sea cores from the North Pacific basin and their bearing on the acoustic provinces of the North Pacific, Tech. Rep, 10,357 pp., Lamont-Doherty Geol. Observ., Columbia Univ., Palisades, N.Y., 1968.

Irving, E., The mid-Atlantic ridge at $45^{\circ} \mathrm{N}, 14$, Oxidation and magnetic properties of basalt; review and discussion, Can. J. Earth Sci., 7, 1528-1538, 1970.

Irving, E., W. A. Robertson, and F. Aumento, The mid-Atlantic ridge near $45^{\circ} \mathrm{N}, 6$, Remanent intensity, susceptibility, and iron content of dredged samples, Can. J. Earth Sci., 7, 226-238, 1970.

Jacobs, M. B., and J. D. Hays, Paleo-climatic events indicated by mineralogical changes in deep-sea sediments, J. Sediment. Petrology, 42, 889-898, 1972.

Johnson, H. P., and R. T. Merrill, Magnetic and mineralogical changes associated with low-temperature oxidation of magnetite, $J$. Geophys. Res., 77, 334-341, 1972.

Kent, D. V., Post-depositional remanent magnetization in deep-sea sediment, Nature, 246, 32-34, 1973.

Kent, D. V., N. D. Opdyke, and M. Ewing, Climate change in the North Pacific using ice-rafted detritus as a climatic indicator, Geol. Soc. Amer. Bull., 82, 2741-2754, 1971.

Larson, E., M. Ozima, M. Ozima, T. Nagata, and D. Strangway, Stability of remanent magnetization of igneous rocks, Geophys. J., 17. 263-292, 1969.

Laughton, A. S., et al., Deep Sea Drilling Project leg 12, Geotimes, 15 , $10-14,1970$.

Løvlie, R., W. Lowrie, and M. Jacobs, Magnetic properties and mineralogy of four deep-sea cores, Earth Planet. Sci. Lett., 15, $157-168,1971$.

Lowrie, W., R. Løvlie, and N. D. Opdyke, Magnetic properties of Deep-Sea Drilling Project basalts from the North Pacific Ocean, J. Geophys. Res., 78, 7647-7660, 1973.

McDougall, I., and H. Wensink, Paleomagnetism and geochronology of the Pliocene-Pleistocene lavas in Iceland, Earth Planet. Sci. Lett., $1,232-236,1966$.

McManus, D. A., O. Weser, C. C. von der Borch, T. Vallier, and R. E. Burns, Regional aspects of deep-sea drilling in the northwest Pacific, in Initial Reports of the Deep-Sea Drilling Project, vol. 5, edited by D. A. McManus et al., pp. 621-636, U.S. Government Printing Office, Washington, D. C., 1970.

Nagata, T., Rock Magnetism, 2nd ed., pp. 245-259, Maruzen, Tokyo, 1961.

Nagata, T., Magnetic properties of ferrimagnetic minerals of $\mathrm{Fe}-\mathrm{Ti}-\mathrm{O}$ system, in Proceedings of the Benedum Earth Magnetism Symposium, pp. 69-86, University of Pittsburgh Press, Pittsburgh, Pa., 1962.

Néel, L., Théorie du trainage magnetique des ferromagnetiques en grains fins et avec applications aux terres cuites, Ann. Geophys.. 5. 99-136, 1949.

Opdyke, N. D., and J. H. Foster, Paleomagnetism of cores from the North Pacific, Geol. Soc. Amer. Mem. 126, 83-119, 1970. 
Opdyke, N. D., D. V. Kent, and W. Lowrie, Details of magnetic polarity transitions recorded in a high deposition rate deep-sea core, Earth Planet. Sci. Lett., 20, 315-324, 1973.

O'Reilly, W., and P. W. Readman, The preparation and unmixing of cation deficient titanomagnetites, $Z$. Geophys., 37, 321-327, 1971.

Ozima, M., and E. E. Larson, Low- and high-temperature oxidation of titanomagnetite in relation to irreversible changes in the magnetic properties of submarine basalts, J. Geophys. Res., 75. 1003-1017, 1970.

Ozima, M., and M. Ozima, Characteristic thermomagnetic curve in submarine basalts, J. Geophys. Res., 76, 2056, 1971.

Pouillard, E., Sur le comportement de l'alumine et de l'oxyde de titane vis-à-vis des oxydes de fer, Ann. Chim., 5, 164-214, 1950.

Readman, P. W., and W. O'Reilly, The synthesis and inversion of non-stoichiometric titanomagnetites, Phys. Earth Planet. Interiors, 4, 121-128, 1970.

Readman, P. W., and W. O'Reilly, Magnetic properties of oxidized (cation-deficient) titanomagnetites $\left(\mathrm{Fe}_{1}, \mathrm{Ti}_{1}, \square\right)_{3} \mathrm{O}_{4}, J$. Geomagn. Geoelec., 24, 69-90, 1972.

Rimbert, F., Sur l'action de champs alternatifs sur des roches portant une aimantation remanente isotherme de viscosité, $C$. $R$. Acad. Sci., 242, 2536-2538, 1959.

Ruddiman, W. F., and L. K. Glover, Vertical mixing of ice-rafted volcanic ash in North Atlantic sediments, Geol. Soc. Amer. Bull., 83. 2817-2836, 1972.

Shimizu, Y., Magnetic viscosity of magnetite, J. Geomagn. Geoelec., II, 125-138, 1960.

Stacey, F. D., The physical theory of rock magnetism, Advan. Phys., I2, 45-133, 1963.

Thellier, E., Sur l'aimantation des terres cuites et ses applications géophysiques, Ann. Inst. Phys. Globe Univ. Paris Bur. Cent. Magn. Terr.. 16. 157-302, 1938.

von der Borch, C. C., and R. W. Rex, Amorphous iron oxide precipitates in sediments cored during leg 5, Deep-Sea Drilling Project, in Initial Reports of the Deep-Sea Drilling Project, vol. 5, edited by D. A. McManus et al., pp. 541-544, U.S. Government Printing Office, Washington, D. C., 1970.

(Received January 23, 1974; revised April 24, 1974.) 